\section{Nutrition\& Metabolism}

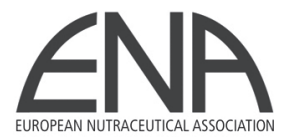

\title{
Scientific Aspects of Weight Management
}

\author{
Conference of the European Nutraceutical \\ Association (ENA)
}

March 10, 2012, Dresden, Germany

\section{Extended Abstracts}

\section{Guest Editors}

Manfred Lamprecht, Graz

Peter Prock, Basel 


\section{Nutritions on Metabolism}

\section{1 \\ Meal Replacements in the Therapy of Obesity}

\section{T. Ellrott}

Institute for Nutrition and Psychology at Göttingen

University Medical School, Germany

Email: thomas.ellrott@gmx.com

Liquid meal replacements are a popular form of a so called "portion-controlled diet". Shakes and meal bars provide patients a fixed quantity of food with a high proportion of protein, a fixed calorie content (i.e., 140 to $220 \mathrm{kcal} / \mathrm{d}$ ) and are usually fully supplemented with micronutrients. In contrast to very low calorie diets, where liquid meal replacements are exclusively used, meal replacement strategies combine one or two daily meal replacements (MR) with conventional foods at the other meals. The German Obesity Association (2007) distinguishes between Step 3 of dietetic treatment of obesity (MR in combination with conventional foods) and Step 4 (full liquid low or very low calorie diet without conventional foods). Wadden et al. (2007) concluded in a comprehensive review, that patients' consumption of portion-controlled diets, including liquid MR (Step 3 of dietetic treatment), was associated with significantly greater shortterm weight loss than was the consumption of isocaloric diets comprised of conventional foods (Wadden et al. 2007).

A meta-analysis by Heymsfield et al. (2003) of six randomized controlled trials found that after 12 months of treatment, participants who used MR maintained a loss 2.4 to $3.4 \mathrm{~kg}$ greater than persons who consumed a diet of conventional foods with the same calorie target. Ditschuneit et al. (1999) found that patients who replaced two meals and two snacks a day with liquid shakes (and snack bar) lost $7.8 \%$ of their initial weight during 3 months of treatment, compared with a loss of only $1.5 \%$ for patients who were prescribed the same number of calories $(1200-1500 \mathrm{kcal} / \mathrm{d})$ but consumed a self-selected diet of conventional foods. After this initial period participants in both groups replaced one meal and one snack a day with a liquid shake or meal bar. Patients in the original (3-month) MR group maintained a loss of $11.3 \%$ of initial weight 2 years after treatment and $8.4 \%$ at a 4 -year follow-up (FlechtnerMors et al. 2000). Patients who were originally treated by the conventional diet but were switched to MR maintained a loss of 3.2\% of initial weight at 4 years. In the Lookahead trial (Wadden et al. 2009) it could be shown in a big sample of obese patients with type 2 diabetes, that there is a clear association between the number of meal replacements used per year and weight loss at 12 months. Patients in the highest quartile of MR usage ( 608 p. a.) lost $11.2 \%$ of initial body weight compared to the lowest quartile of MR usage (117 p. a.) with $5.9 \%$.

MRs are a helpful dietetic strategy for obese subjects to limit energy intake, mainly because obese individuals generally underestimate their food intake by $30 \%$ to $50 \%$ when eating a diet of conventional foods (Lichtman et al. 1992). This is attributable to misjudging portion sizes, failing to recognize hidden sources of energy, and/or forgetting some of the foods consumed.
To maximize treatment success MR as a dietetic strategy should be combined with behavior modification (counseling), increasing physical activity and - depending on individual risk and previous efforts - pharmacological therapy.

\section{References}

German Obesity Association. Evidenzbasierte Leitlinie - Prävention und Therapie der Adipositas - Version 2007. PDF-document at the associations website www.adipositas-gesellschaft.de.

Wadden TA, Butry ML, Wilson C: Lifestyle modification for the management of obesity. Gastroenterology 2007;132:2226-2238.

Heymsfield SB, van Mierlo CA, van der Knaap HC, Heo M, Frier HI: Weight management using a meal replacement strategy: meta and pooling analysis from six studies. Int J Obes 2003;27:537-549.

Ditschuneit HH, Flechtner-Mors M, Johnson TD, Adler G: Metabolic and weight-loss effects of a long-term dietary intervention in obese patients. Am J Clin Nutr 1999;69:198-204.

Flechtner-Mors M, Ditschuneit HH, Johnson TD, Suchard MA, Adler G: Metabolic and weight loss effects of long-term dietary intervention in obese patients: four-year results. Obes Res 2000;8:399-402.

Wadden TA, West DS, Neiberg RH, et al: One-year weight losses in the Look AHEAD study: factors associated with success. Obesity (Silver Spring) 2009;17:713-722.

Lichtman SW, Pisarska K, Berman ER, et al: Discrepancy between selfreported and actual caloric intake and exercise in obese subjects. N Engl J Med 1992;327:1893-1898.

2

\section{Functional Ingredients and Foods: Targeting Satiety for Appetite Control and Weight Management Health Claims}

\author{
J.C.G. Halford \\ Experimental Psychology, University of Liverpool, L69 \\ 7ZA, UK \\ Email: j.c.g.halford@liverpool.ac.uk
}

There is a clear demand for products that help consumers manage their own body weight (induce weight loss and/or prevent weight gain or regain). Such products need to make a direct contribution to effective appetite control. Few approaches, with the exception of meal replacements and very low calorie diets, have been approved by the European Food Safety Authority (EFSA) for either appetite control or weight management. Draft guidance indicates that EFSA are looking for clear sustainable effects on appetite, across multiple meals, across the day, in experimental studies and a durability of effect that is apparent for at least 28 days of product use [1]. Nonetheless, despite the weakness of the current evidence base we have the protocols and measures to substantiate appetite and weight related health claims [2].

Foods that strengthen within-meal satiation and post-meal satiety increase feelings of fullness that control meal-size and reduce feelings of hunger between meals $[2,3]$. This has the potential to reduce

\section{KARGER \\ Fax +41613061234 \\ E-Mail karger@karger.ch}

www.karger.com
(C) 2012 S. Karger AG, Basel

0250-6807/12/0602-0124\$38.00/0

Accessible online at:

www.karger.com/anm 
energy intake by decreasing the amount consumed both at and between meals. If these effects are sustained across the day and endure over repeated exposure, such foods have potential for weight management. All consumption inhibits eating behaviour to some extent, an effect determined by the composition and energy content of the food or beverage. The strength and timing of these signals is largely dependent on the sensory, physical and chemical properties of the food or drink. It is therefore important to consider i) the appearance and sensory impact of foods and beverages, ii) the mechanics of their digestion, iii) the pre-absorptive effects of their constituents within the gastrointestinal tract, and iv) the post-absorptive effects of the products of digestion. Functional ingredients and changes in food structure can influence the release of peripheral factors, such as gut hormones like Ghrelin, CCK, GLP-1 and PYY, that regular gut function. The release of these gut peptides in response to various nutrients can have potent effects on appetite, in part through delaying gastric emptying, which strengthens and prolongs the inhibition of eating behaviour.

A variety of ingredients produce such effects including proteins, slowly digestible carbohydrates and various fibre types, influencing appetite [3]. Data is often equivocal, as effectiveness of these ingredients is dependent on i) the foods into which they are combined, ii) the timing of measures within protocols, and iii) the appropriateness of the chosen control. Nonetheless, such studies provide important proof-ofconcept from which potential products can be developed. This requires that the product used in the study is sufficiently similar to the end product, and the behavioural evidence from the study is sufficient to support the actual intended use. Certain oil-based products have also been shown to influence appetite [3]. These effects are consistent with the effects of free fatty acids, chain length 12 and above, in the small intestine on CCK, GLP-1 and/or PYY which delay gastric emptying and oro-cecal transit. The effects of oat and palm oil on appetite were established in early trials although subsequent studies have not replicated these effects [4-8]. Nonetheless, like many approaches, the effectiveness of this ingredient has yet to be fully optimised through food formulation. Modifications to food structure may provide opportunities for innovation and this can be tested with biomarkers in vitro and in vivo.

The benefits of satiety-enhancing ingredients to both consumers and their health are under research. It is possible that such ingredients help consumers gain control over their eating behaviour and may also help reduce the negative psychological impact of dieting and the physiological consequences of energy restriction, inducing changes in gut hormone function [9]. The challenge remains to demonstrate their enduring effects on appetite and energy intake, and the health and consumer benefits such effects provide in terms of optimising successful weight management.

\section{References}

1. EFSA Panel on Dietetic Products, Nutrition and Allergies (NDA): DRAFT SCIENTIFIC OPINION 1 - Guidance on the scientific requirements for health claims related to appetite ratings, weight management, and blood glucose concentrations. EFSA Journal 20xx; $x(x)$ :xxx.

2. Blundell JE, de Graaf C, Hulshof T, et al: Appetite Control: methodological aspects of the evaluation of foods. Obesity Reviews 2010;11:251-270.

3. Halford JCG: What's new in the appetite suppressant field? A nutritional and behavioural perspective. Agro-Food Industry Hi-Tech 2007;18:28-30.

4. Burns AA, Livingstone MBE, Welch RW, et al: Dose-response effects of a novel fat emulsion $\left(\mathrm{Olibra}^{(\mathrm{TM})}\right)$ on energy and macronutrient intakes up to 36h post consumption. Eur J Clin Nutr 2002;56:368-377.

5. Haenii A, Sundberg B, Yazdanpanah N, et al: Effect of fat emulsion (Fabuless) on orocecal transit time in healthy men. Scand J Gastroenterol 2009;44:1186-1190.
6. Logan CM, McCaffrey TA, Wallace JMV, et al: Investigation of the medium-term effects of Olibra ${ }^{(\mathrm{TM})}$ fat emulsion on food intake in nonobese subjects. Eur J Clin Nutr 2006;60:1081-1091.

7. Smit HJ, Keenan E, Kovacs EMR, et al: No efficacy of processed Fabuless (Olibra) in suppressing appetite or food intake. Eur J Clin Nutr 2011;65:81-86.

8. Olsson J, Sundberg B, Vibert A, et al: Effect of a vegetable-oil emulsion on body composition; a 12 week study in overweight women on a meal replacement therapy after an initial weight loss: a randomised controlled trial. Eur J Nutr 2011;50:235-242.

9. Sumithran P, Prendergast LA, Delbridge E, et al: Long-term persistence of hormonal adaptations to weight loss. NEJM 2011;365:1597-1604.

\section{3 \\ Motivation, Volition and Weight Management}

\section{R. Fuchs}

Institute of Sport and Sport Science, University of Freiburg, Germany

Email: reinhard.fuchs@sport.uni-freiburg.de

Weight management is based on a lifestyle which involves regular physical activity and a healthy (well-balanced) diet. Intervention programs for treating overweight and adiposity which focus on dietary change and physical exercise often do not lead to the desired long-term reduction in weight and thus to an improved state of health (Douketis et al., 2005; Perri \& Corsica, 2002; Stevens, Truesdale, McClain \& Cai, 2006). Most participants in such programs lose approximately $10 \%$ of their initial body weight within six months (National Institutes of Health, 1998). However, long-term evaluation of one-year follow-up programs shows weight loss of at least $10 \%$ of initial weight only for a fifth of the participants in a program (Wing \& Phelan, 2005). Jakicic et al. (2008) report weight loss of at least $10 \%$ at 24 months for approximately $30 \%$ of participants, but only when they reach high levels of physical exercise ( $275 \mathrm{~min} /$ week). In Germany, it is estimated that only $25 \%$ of participants in weight-loss programs succeed in maintaining a weight loss of at least 5\% at a three-year follow-up (Westenhöfer, 2005). In an overview of 23 interventions, Sharma (2007) reports that only two were conducted by trained personnel and that the majority of them lacked a standardized behavioral basis. Moreover, most of the interventions were based on theoretical considerations which were almost exclusively concerned with the influence of motivation (Franz et al., 2007). Research shows that people are often highly motivated to adopt a healthy lifestyle; however, they do not succeed of actually accomplishing this. They require help in making and implementing concrete plans (so-called implementation intentions; Gollwitzer, 1999) and shielding them against confounding factors in daily life.

M.O.B.I.L.I.S. is a standardized and theory-driven interdisciplinary training program for adipose adults (Berg et al., 2008; 2010; Göhner \& Fuchs, 2006). In addition to an exercise program and dietary advice, the program offers participants medical supervision and comprehensive psychological support by skilled trainers. The psychological support is based on the MoVo concept (Fuchs, Göhner \& Seelig, 2011; Göhner, Seelig \& Fuchs, 2009) that was designed to serve both to motivate the participants and, most importantly, to help them reach their targets and implement their plans. The MoVo concept integrates central elements of social cognition research with a strong focus on motivational 
aspects (Conner \& Norman, 2005; Rutter \& Quine, 2002) as well as central elements of action control theories (de Ridder \& de Wit, 2006), which emphasize the volitional (self-regulatory) side of behavioral control (Baumeister \& Vohs, 2004). According to the MoVo concept, engaging in physical exercise and maintaining a healthy diet requires positive outcome expectations, high self-efficacy, strong goal intentions, concrete action plans, effective barrier management, and positive outcome experiences (Fuchs et al., 2011, Göhner et al., 2009).

This presentation reports on the effectiveness of the intervention program. Participants were taught cognitive-behavioral strategies of goal setting, action planning, barrier management and self-monitoring. $N=316$ persons with obesity followed a public advertisement to participate in the intervention program (IG) or comparison group (CG) (quasi-experimental design). Assessments were conducted at four time points, with the last assessment being conducted two years after baseline. At the 24-month follow-up, the IG showed weight loss of 5.57\%, whereas the CG lost $1.12 \%$ of their weight (t1-t4, p $<.01$ ). The results yielded significant interaction terms (group $\mathrm{x}$ time), indicating that the intervention had a substantial effect on food choice and level of physical exercise $(\mathrm{p}<.01)$. The IG showed significantly enhanced self-efficacy, stronger goal intentions, and a more concrete action planning than the CG at follow-ups.

These findings suggest that intervention programs based on the MoVo concept have the potential to evoke enduring changes in the cognitions we hypothesized to be responsible for inducing obese adults to begin and continue regular exercise and healthy eating behavior, resulting in substantial weight loss. The presentation will discuss implications for further research and practice in the realm of weight management.

\section{References}

Baumeister RF, Vohs KD: Self-regulation. New York: Guilford Press, 2004

Berg A Jr, Frey I, Hamm M, Fuchs R, Göhner W, Lagerström D, Predel H-G, Berg A: Das M.O.B.I.L.I.S.-Programm. Adipositas 2008;2:90-95.

Berg A, Frey I, Hamm M, Lagerström D, Haas U, Fuchs R, Göhner W, Predel H, Berg A: Patientenschulung im Bereich Adipositas: Das bewegungsorientierte M.O.B.I.L.I.S.-Konzept. Bewegungstherapie und Gesundheitssport 2010;26:58-64.

Conner M, Norman P: Predicting health behavior: Research and practice with social cognition models ( 2 ed.) Maidenhead, UK: Open University Press, 2005 .

de Ridder D, de Wit J: Self-regulation in health behavior. London: Wiley, 2006.

Douketis JE, Blair SN, Jakicic JM, Manore MM, Ranking JW, Smith BK: Systematic review of long-term weight loss studies in obese adults: clinical significance and applicability to clinical practice. International Journal of Obesity 2005;29:1153-1167.

Franz MJ, Jeffrey J, VanWormer MS, Crain L, Boucher JL, Histon T, et al: Weight-loss outcomes: a systematic review and meta-analysis of weightloss clinical trials with a minimun 1-year follow-up. Journal of the American Dietetic Association 2007;107:1755-1767.

Fuchs R, Göhner W, Seelig H: Long-term effects of a psychological group intervention on physical exercise and health: The MoVo concept. Journal of Physical Activity and Health 2011;8:794-803.

Göhner W, Fuchs R: M.O.B.I.L.I.S. Standardisiertes Trainer Manual Verhalten. Interne Schulungsunterlagen (M.O.B.I.L.I.S. standardized trainer manual on behaiovr. Internal training documentation). Freiburg: Universitätsklinikum, 2006.

Göhner W, Seelig H, Fuchs R: Intervention effects on cognitive antecedents of physical exercise: a 1-year follow-up study. Applied Psychology: Health and Well-Being 2009;1:233-256.

Gollwitzer PM: Implementation Intentions. Strong effects of simple plans. American Psychologist 1999;54:493-503.

Jakicic JM, Marcus BH, Lang W, Janney C: Effect of exercise on 24-month weight loss maintenance in overweight women. Archives of Internal Medicine 2008;168:1550-1559.
National Institutes of Health: Clinical guidelines on the identification, evaluation, and treatment of overweight and obesity in adults: the evidence report. Obesity Research 1998;6:51S-209S.

Perri M, Corsica L: Improving the maintenance of weight lost in behavioral treatment of obesity. In T. Wadden \& A. Stunkard (Eds.), Handbook of obesity treatment. New York: Guilford Press, 2002, pp 357-379.

Rutter D, Quine L: Changing health behaviour: Intervention and research with social cognition models. In D. Rutter \& L. Quine (Eds.), Intervention and research with social cognition models. Buckingham, UK: Open University Press, 2002, pp 434-466.

Sharma M: Behavioural interventions for preventing and treating obesity in adults. Obesity Reviews 2007;8:441-449.

Stevens J, Truesdale KP, McClain JE, Cai J: The definition of weight maintenance. International Journal of Obesity 2006;30:391-399.

Westenhöfer J: Evaluierte Therapieprogramme in Deutschland - wer spricht darauf an (evaluated therapy programs in Germany - for whom does it work). In H. Ebersdobler, H. Heseker, \& G. Wolfram (Eds.), Adipositas - eine Herausforderung für's Leben (Obesity - a lifetime challenge). Stuttgart: Wissenschaftliche Verlagsgesellschaft mbH, 2005, pp 169-184.

Wing RR, Phelan S: Long-term weight loss maintenance. American Journal of Clinical Nutrition 2005;82:222S-225S.

\section{4 \\ Internet-Based Approaches in Weight Management}

D. Lange

Institute of Psychology, Division of Health Psychology

Freie Universität Berlin, Germany

Email: daniela.lange@fu-berlin.de

Objective: Overweight and obesity increase a person's risk of developing non-communicable diseases, shortening life expectancy and adversely affecting the quality of life [1]. Given the steady rise in the prevalence of overweight and obesity [2], effective intervention strategies for weight management are required. Due to the fact that obesity and overweight are social phenomena linked with alterable lifestyle issues [3, 4], the epidemic trend is reversible. The WHO's recommendations for preventing and managing weight gain emphasize the need for early prevention to ensure lifelong healthy eating and physical activity patterns [5].

Challenging Situation: Despite their high motivation to change their lifestyle, the majority of people fail to follow the recommendations for physical activity and a healthy diet. This phenomenon has been labelled the intention-behaviour gap [6], and should be considered in intervention strategies. Moreover, treatments should be based on a comprehensive weight management program to produce and maintain weight loss over a long period of time. However, most participants of a behavioral intervention regain about one third of their weight lost within 1 year, and they are typically back to baseline in 3 to 5 years [7, 8]. Furthermore, high attrition rates are common in traditional weight management programs, caused by time and travel demands $[9,10]$ or senses of shame thatobese individuals could perceive attending treatment sessions delivered in face-to-face formats [11]. In addition, interventions may be not matched to participants' individual needs [12]. Hence, developing effective long-term weight management programs that are time- and cost-saving, appealing and widely accessible as well as matched to the participants' individual needs has become the main challenge in the treatment of overweight and obesity.

Internet-based Solution: Internet-based weight management programs show great promise for this challenge, because they have 
the potential to overcome most of the limits associated with traditional weight-loss programs. They offer a number of novel opportunities for self-help programs and allow health care professionals to maintain longterm contact with large numbers of individuals in a time- and cost-saving manner [13]. Moreover, internet-based approaches allow for an individualized feedback and a tailoring intervention, matched to participants' individual needs and prerequisites. Although the empirical evidence of such programs has been found inconsistent [14], systematic reviews recently pointed to the effectiveness of internet-based interventions in achieving significant weight loss and weight loss maintenance $[15,16]$. However, the evidence of effectiveness is modest. Thus, it is important to prioritize well-designed efficacy trials that account for known sources of variation and determine which features of internet-based interventions are critical to achieve success in weight management.

Theory-based Solution: A prerequisite for suitable interventions is the establishment of a theoretical framework. Health behaviour theories help to predict, explain, and influence the mechanisms of health behaviour change [17]. Stages of change theories assume that the adoption and maintenance of health behaviours proceed through an ordered series of discrete stages. Individuals at different stages are characterized by different mindsets, delineated by differences in terms of their cognitions, perceived barriers and action tendencies. According to such theories, interventions can be matched to a person's stage by targeting stage-specific needs [18]. These stage-matched interventions have the potential to bemore effective than 'one size fits all'-interventions, and less costly, time-consuming, and reactance inducing because irrelevant and redundant messages can be avoided.

Promising Approach: Changing dietary and activity behaviors such as weight management requires not only basic knowledge about it, but also motivational and volitional factors that guide self-regulatory processes [19]. Stage-matched interventions derived from a theoretical framework such as the Health Action Process Approach (HAPA) [20, 21] would be directed at these proposed stage-specific social-cognitive variables. The HAPA has several principles. The first principle suggests that one should divide the health behavior change process into two phases (motivation and volition) in which people develop their intentions. There is a switch of mindsets when people move from deliberation to action. In the volition phase there are two groups of individuals: those who have not yet translated their intentions into action, and those who have. Thus, one can also create three categories of people with different mindsets: Preintenders, intenders, and actors. Intenders who are in the volitional preactional stage are motivated to change, but do not act because they might lack the right skills to translate their intention into action. Planning is a key strategy at this point. It can be divided into action planning and coping planning. Perceived self-efficacy is required throughout the entire process. As several randomized controlled trials have documented the evidence in favor of such interventions in the context of dietary behaviours $[22,23]$ as well as physical activity $[24,25]$, theory-based intervention programs that are delivered via the internet appear to be a novel and promising approach.

Prospects: Some of these considerations have also been incorporated in multiple health behavior change interventions in Germany. The presentation at the expert workshop will refer to one example of a web-based coach and will illustrate opportunities and challenges of such an approach.

\section{References}

1. Branca FNH, Lobstein T: The Challenge of Obesity in the WHO European Region and the Strategies for Response: Summary 2007 [Internet], Copenhagen: WHO Regional Office for Europe.
2. Organization WH: Fact sheet $\mathrm{N}^{\circ} 311$ Obesity and overweight. Available from:http://www.who.int/mediacentre/factsheets/fs311/en/index.html.2011 [updated March 2011].

3. Goran MI, Weinsier RL: Role of environmental vs. metabolic factors in the etiology of obesity: time to focus on the environment. Obesity research 2000;8:407-409. Epub 2000/09/01. doi:10.1038/oby.2000.50. PubMed PMID:10968734.

4. Popkin BM, Gordon-Larsen P: The nutrition transition: worldwide obesity dynamics and their determinants. International journal of obesity and related metabolic disorders : journal of the International Association for the Study of Obesity. 2004;28(Suppl 3):S2-S9. Epub 2004/11/16. doi:10.1038/sj.ijo.0802804. PubMed PMID:15543214.

5. Organization WH: Report of the meeting on community initiatives to improve nutrition and physical activity. Berlin, Germany, 21-22 February 2008. Copenhagen: WHO Regional Office for Europe, 2010.

6. Sheeran P: Intention-behaviour relations: A conceptual and empirical review. In: European Review of Social Psychology [Internet]. London: Wiley, 2002, pp 1-36.

7. Wing RR, Tate DF, Gorin AA, Raynor HA, Fava JL: A self-regulation program for maintenance of weight loss. The New England journal of medicine 2006;355:1563-1571. Epub 2006/10/13. doi:10.1056/ NEJMoa061883. PubMed PMID:17035649.

8. Katan MB: Weight-loss diets for the prevention and treatment of obesity. The New England journal of medicine 2009;360:923-925. Epub 2009/02/28. doi:10.1056/NEJMe0810291. PubMed PMID:19246365.

9. Wadden TA, Crerand CE, Brock J: Behavioral treatment of obesity. The Psychiatric clinics of North America 2005;28:151-170, ix. Epub 2005/03/01. doi:10.1016/j.psc.2004.09.008. PubMed PMID:15733617.

10. Levy RL, Finch EA, Crowell MD, Talley NJ, Jeffery RW: Behavioral intervention for the treatment of obesity: strategies and effectiveness data. The American journal of gastroenterology 2007;102:2314-2321. Epub 2007/06/15. doi:10.1111/j.1572-0241.2007.01342.x. PubMed PMID:17561967.

11. Polzien KM, Jakicic JM, Tate DF, Otto AD: The efficacy of a technology-based system in a short-term behavioral weight loss intervention. Obesity (Silver Spring) 2007;15:825-830. Epub 2007/04/12. doi:10.1038/ oby.2007.584. PubMed PMID:17426316.

12. Noar SM, Benac CN, Harris MS: Does tailoring matter? Meta-analytic review of tailored print health behavior change interventions. Psychological bulletin 2007;133:673-693. Epub 2007/06/27. doi:10.1037/0033-2909. 133.4.673. PubMed PMID:17592961.

13. Weinstein PK: A review of weight loss programs delivered via the Internet. The Journal of cardiovascular nursing 2006;21:251-258; quiz 9-60. Epub 2006/07/11. PubMed PMID:16823276.

14. Arem H, Irwin M: A review of web-based weight loss interventions in adults. Obesity reviews : an official journal of the International Association for the Study of Obesity. 2011;12:e236-e243. Epub 2010/09/02. doi:10.1111/j.1467-789X.2010.00787.x. PubMed PMID:20804523; PubMed Central PMCID:PMC3086798.

15. Neve M, Morgan PJ, Jones PR, Collins CE: Effectiveness of web-based interventions in achieving weight loss and weight loss maintenance in overweight and obese adults: a systematic review with meta-analysis. Obesity reviews: an official journal of the International Association for the Study of Obesity. 2010;11:306-321. Epub 2009/09/17. doi:10.1111/ j.1467-789X.2009.00646.x. PubMed PMID:19754633.

16. Manzoni GM PF, Corti S, Molinari E, Castelnuovo G: Internet-based behavioral interventions for obesity: an updated systematic review. Clin Pract Epidemiol Ment Health 2011;7:19-28.

17. Schwarzer R: Health behavior change. Friedman HS, editor. New York: Oxford University Press, 2011.

18. Weinstein ND, Rothman AJ, Sutton SR: Stage theories of health behavior: Conceptual and methodological issues. Health Psychology 1998;17:290299. doi:10.1037/0278-6133.17.3.290. PubMed PMID:hea-17-3-290.

19. Schwarzer R, Lippke S, Luszczynska A: Mechanisms of health behavior change in persons with chronic illness or disability: The Health Action Process Approach (HAPA). Rehabilitation Psychology 2011;56:161-170. doi:10.1037/a0024509. PubMed PMID:rep-56-3-161.

20. Schwarzer R: Self-efficacy in the adoption and maintenance of health behaviors: Theoretical approaches and a new model. In: Schwarzer R, editor. Self-efficacy: Thought control of action. Washington, DC: Hemisphere 1992, p 217-243. 
21. Schwarzer R, Luszczynska A: How to overcome health-compromising behaviors: The health action process approach. European Psychologist 2008;13:141-151. doi:10.1027/1016-9040.13.2.141. PubMed PMID: epp13-2-141.

22. de Vet E, de Nooijer J, de Vries NK, Brug J: Testing the Transtheoretical model for fruit intake: Comparing web-based tailored stage-matched and stage-mismatched feedback. Health Education Research 2008;23:218227. doi:doi:10.1093/her/cym019.

23. Kreausukon P, Gellert P, Lippke S, Schwarzer R: Planning and self-efficacy can increase fruit and vegetable consumption: a randomized controlled trial. Journal of Behavioral Medicine 2011, Epub 2011/08/09. doi: 10.1007/s10865-011-9373-1. PubMed PMID:21822980.

24. Lippke S, Schwarzer R, Ziegelmann JP, Scholz U, Schuz B: Testing stagespecific effects of a stage-matched intervention: a randomized controlled trial targeting physical exercise and its predictors. Health education \& behavior: the official publication of the Society for Public Health Education. 2010;37:533-546. Epub 2010/06/16. doi:10.1177/1090198109359386. PubMed PMID:20547760.

25. Koring M, Richert J, Parschau L, Ernsting A, Lippke S, Schwarzer R: A combined planning and self-efficacy intervention to promote physical activity: A multiple mediation analysis. Psychology, Health and Medicine 2011, Epub 2011/10/20. doi:10.1080/13548506.2011.608809. PubMed PMID: 22007933.

\section{5 \\ Influence of an Encapsulated Fruit, Berry and Vegetable Juice Concentrate and Walking Exercise on Oxidative Stress and Skin Microcirculation in Overweight Women}

\author{
M. Lamprecht ${ }^{1,2}$, G. Obermayer ${ }^{1,2}$, J.F. Greilberger ${ }^{1,5}$, \\ K. Steinbauer', L. Hofmann', S. Hallstroem'1', G. Juergens', \\ S.G. Cvirn ${ }^{1}$ \\ ${ }^{1}$ Institute of Physiological Chemistry, Centre for \\ Physiological Medicine, Medical University of Graz, Graz, \\ Austria, ${ }^{2}$ Green Beat - Institute of Nutrient Research and \\ Sport Nutrition, Graz, Austria, ${ }^{3}$ SportchirurgiePlus, Centre \\ for Individual Sport Medicine and Surgery, Graz, Austria, \\ ${ }^{4} \mathrm{FH}$ Joanneum, University of Applied Sciences, Graz, \\ Austria, ${ }^{5}$ Institute of Laboratory Sciences, Dr Greilberger \\ $\mathrm{GmbH}$, Laßnitzhöhe, Austria
}

Introduction: Juice Plus $+\circledR$ (Memphis, Tennessee, USA), a whole food based nutraceutical, contains various phytochemicals like polyphenols, anthocyanins, carotenoids, vitamins and other compounds. Recent studies have demonstrated that this product improves skin microcirculation and reduces concentrations of oxidative stress markers at rest and post exercise in different cohorts of subjects $[1,2,3]$. But up to now overweight and/or obese women have not been investigated with this juice concentrate for aspects of oxidative stress and skin microcirculation in combination with postulated health-promoting exercise.

Methods: A randomized, double-blinded, placebo controlled clinical trial to observe the influence of Juice Plus $+\circledR$ supplementation on markers of oxidation and skin microcirculation at rest and post exercise was performed. The overweight and obese women (BMI: 28.4-39.8, stratified by weight between the study groups) were premenopausal ( $42 \pm 5$ years), non-smokers, and were recruited to perform a standardized 30 minutes treadmill walking test at $70 \%$ of $\mathrm{VO}_{2 \max }$ before and after 8 weeks of supplementation with study capsules. Three fruit, berry, and vegetable capsules or placebo capsules were given twice per day ( $2 \times 3$ capsules with meals $=6$ capsules daily). The markers of plasma oxidation we determined were: carbonyl proteins (CP), malondialdehyde (MDA), total oxidation status (TOS). Parameters of skin microcirculation were assessed at skin depths $1 \mathrm{~mm}$ and $8 \mathrm{~mm}$ : oxygen saturation of hemoglobin $\left(\mathrm{SO}_{2} \mathrm{Hb}\right)$, relative concentration of hemoglobin $(\mathrm{rHb})$, blood flow through skin capillaries (BF). Venous blood for oxidation markers were collected before and immediately after 30 minutes of walking exercise at $70 \%$ of individual $\mathrm{VO}_{2 \max }$. Microcirculation was measured by $\mathrm{O} 2 \mathrm{C}$-technique on the back of the wrist before and $10 \mathrm{~min}$ post exercise. Individual $\mathrm{VO}_{2 \max }$ was determined before the intervention period as part of eligibility testing. Subjects were instructed to wash-out four weeks from any supplements before the 1 st exercise test/blood collection, to follow nutritional presets before each exercise testing/blood collection, and to avoid physical exercise training, weight loss and specific dietary regimens for the eight week duration of the nutraceutical intervention. Statistical analysis was performed via multifactorial analysis of variance (ANOVA, factors: treatment $=$ comparison of supplementation versus placebo, time $=$ pre vs. post exercise, exercise $=$ walking test 1 vs. walking test 2). Level of significance was set at $\mathrm{p}<0.05$.

Results: The presented results are interim results of an ongoing study with more than 40 overweight and obese women. Up to now we analysed parameters for 32 or 21 subjects. We found a significant reduction of TOS values in the supplemented group $\left(\mathrm{N}=32, \mathrm{p}_{\text {treat }}<0.05\right)$, and a decrease in $\mathrm{CP}$ with a tendency $\left(\mathrm{N}=21, \mathrm{p}_{\text {treat }}=0.059\right)$. There were no other influences observed on oxidation markers. $\mathrm{SO}_{2} \mathrm{Hb}$ in $1 \mathrm{~mm}$ skin depth increased significantly in the supplemented group $(\mathrm{N}=32$, $\mathrm{p}_{\text {treat }}<0.05$ ). There was no influence of other factors on $\mathrm{SO}_{2} \mathrm{Hb}$ in $1 \mathrm{~mm}$ skin depth. Exercise affected $\mathrm{SO}_{2} \mathrm{Hb}$ significantly in $8 \mathrm{~mm}$ skin depth to increased values post exercise compared to pre exercise $(\mathrm{N}=32$, $\left.\mathrm{p}_{\text {time }}<0.05\right)$. There was no other influence on this variable in $8 \mathrm{~mm}$ skin depth. $\mathrm{rHb}$ in $1 \mathrm{~mm}$ and $8 \mathrm{~mm}$ skin depth increased significantly from pre to post exercise $\left(\mathrm{N}=32, \mathrm{p}_{\text {time }}<0.05\right)$. No influence of other factors on $\mathrm{rHb}$ was observed. $\mathrm{BF}$ in $1 \mathrm{~mm}$ and $8 \mathrm{~mm}$ skin depth also increased significantly from pre to post exercise $\left(\mathrm{N}=32, \mathrm{p}_{\text {time }}<0.05\right)$ with no influence of other factors

Conclusion: These data show that the nutraceutical decreased oxidation status in plasma and increased oxygenation of hemoglobin in the skin surface. Exercise also improved skin oxygenation and increased microcirculatory blood flow in the skin, with increased hemoglobin concentrations. We hypothesise that the juice concentrate exerted antioxidant effects to reduce oxidation and provided nutrients that stimulated NO-metabolism for better skin oxygenation. Exercise also affected NO-metabolism to increase skin oxygenation and skin microcirculation. However, in comparison to the effects of one single influencing factor (factor supplementation or factor exercise), this study also demonstrates a better beneficial outcome on redox homeostasis and skin microcirculation in overweight and obese women when both influencing factors are combined.

\section{References}

1. DeSpirt S, Sies H, Tronnier H, et al: An encapsulated fruit and vegetable juice concentrate increases skin microcirculation in healthy women. Skin Pharmacol Physiol 2012;25:2-8.

2. Lamprecht M, Oettl K, Schwaberger G, et al: Protein modification responds to exercise intensity and antioxidant supplementation. Med Sci Sports Exerc 2009;41:155-163.

3. Bloomer RJ, Goldfarb AH, McKenzie MJ: Oxidative stress response to aerobic exercise: Comparison of antioxidant supplements. Med Sci Sports Exerc 2006;38:1098-1105. 


\section{Author Index}

\section{Annals of Nutrition\& Metabolism}

Cvirn, S.G. 5

Ellrott, T. 1

Fuchs, R. 3

Greilberger, J.F. 5
Halford, J.C.G. 2

Hallstroem, S. 5

Hofmann, L. 5

Juergens, G. 5

Lamprecht, M. 5
Lange, D. 4

Obermayer, G. 5

Steinbauer, K. 5 